REVISTA ANDALUZA DE ANTROPOLOGÍA

NÚMERO 15: ACTIVIDADES TURÍSTICAS, CIUDAD Y PATRIMONIO CULTURAL: MIRADAS CRÍTICAS. TOURIST ACTIVITIES, CITY AND CULTURAL HERITAGE: CRITICAL GLANCES

SEPTIEMBRE DE 2018

ISSN 2174-6796

[pp. 216-221]

http://dx.doi.org/10.12795/RAA.2018.15.11

\title{
RUIZ MORALES, FERNANDO C. y CÁCERES, RAFAEL (2018). Pepa Vargas. Memoria de una mujer flamenca. Sevilla: Athenaica, Ediciones Universitarias, 308 pp.
}

\section{Cristina Cruces Roldán}

Catedrática de Antropología Social / Grupo de Investigación GEISA

La bibliografía flamenca se ha nutrido del género biográfico casi desde los albores del flamenco mismo. Ya en 1881, Antonio Machado y Álvarez Demófilo se sirvió de Juanelo de Jerez para proporcionarnos una primera semblanza biográfica del mítico cantaor Silverio Franconetti. Desde entonces y hasta hoy, y exceptuadas historias fílmicas y algunas autobiografías, los dos enfoques privilegiados para conocer negro sobre blanco a las individualidades jondas (con frecuencia grandes artistas, casi siempre hombres, que han marcado época) han sido las biografías elaboradas a partir de evidencias documentales, y los relatos de vida construidos a partir de entrevistas directas. La propia naturaleza del flamenco, la condición diletante de bastantes trabajos, y la miscelánea de situaciones que se abren dentro del concepto posible de "investigación", ha dado lugar históricamente a una amalgama de títulos de calidad muy desigual, tanto en lo metodológico como en lo literario, que a veces no superan la tentación de convertirlos en meras listas de sucedidos descriptivos o sucesiones de documentos registrales, ni siquiera alcanzan una correcta contextualización de los protagonistas, o aplican rigurosas técnicas de obtención de datos, clasificación y análisis de resultados. 
Una muestra de cómo elaborar memorias personales que son, a la vez, una agradecida lectura y un recorrido histórico que trasciende la personalidad del caso, es la obra de los profesores de la UPO Fernando Ruiz Morales y Rafael Cáceres Feria sobre la cantaora gitana Pepa Vargas. Curtidos en investigación sobre temas flamencos, con títulos bien conocidos sobre emigración, género o historia cultural, los autores optan por elegir a una entrañable intérprete, tal vez secundaria, para testimoniar las experiencias de las mujeres flamencas nacidas en los territorios de la Baja Andalucía a mediados del siglo XX, las singularidades de su acceso (o no) a la profesión de artista, y su rol estructural en la vivencia y transmisión de la cultura flamenca. Fascinados por el discurso de Pepa en una de las sesiones convocadas por la peña flamenca universitaria de la UPO, el trabajo de Ruiz y Cáceres es fruto de entrevistas abiertas y recopilación documental esta última ciertamente no muy extensa-, cuyos resultados van más allá de recuerdos, valoraciones y expectativas de la biografiada sobre su mundo flamenco. Cierran en torno a ella un coro de voces acerca de la estructura genealógica y territorial del flamenco "de origen" (para el que Pepa fue niña, hija, esposa y madre), la profesionalización tardía impelida, como en otros muchos casos, por circunstancias sociofamiliares, y el devenir contemporáneo del propio género jondo. Un arte del que participan hoy, desde otras experiencias y evaluaciones, tres hijos de Pepa: la cantaora Esperanza Fernández, el guitarrista Paco Fernández y el bailaor Joselito Fernández. Junto a Curro Fernández, su marido y ejemplo de "cantaor de atrás" (para el baile), formaron durante las décadas de los ochenta y noventa la reconocida "Familia Fernández", cuya formación, planificación, componentes, repertorios, estrategias creativas y trayectoria son sacadas a la luz por primera vez de forma pormenorizada gracias a Pepa Vargas. Memoria de una mujer flamenca.

Desfilan también por el libro el devenir profesional de algunos familiares próximos como la bailaora Concha Vargas, hermana de Pepa, y la reivindicación de otros intérpretes de variadas épocas, con su buena dosis de semblanza y anecdotario, demostrando que las obsesiones documentalistas de un historicismo mal entendido tienen alcance limitado frente a las fuentes orales si se quieren acometer con rigor los estudios sobre la cultura popular. Esos relatos se convierten en llamadas al "arte con mayúscula" para glosar, entre otras, las figuras de Antonio Mairena, Fernanda y Bernarda de Utrera, Juan Talega, Manuela Vargas, Matilde Coral, Lole, Manuel Molina, Raimundo Amador o Juana del Revuelo, pero también emergen de ellos otros muchos flamencos que conocieron de raíz de este grandioso patrimonio musical, pero no alcanzaron a convertirse en profesionales o desaparecieron de los anales flamencos. Singularmente, un rosario de mujeres que - frente al negacionismo sobre las desigualdades de género que persiste en una parte notable de la afición- evidencian gracias a los hechos y testimonios de Pepa las trabas femeninas para profesionalizarse, o tan siquiera para practicar el cante o el baile en las reuniones familiares. Su presencia en el flamenco se nos aparece subordinada 
a decisiones básicamente masculinas de padres, hermanos o maridos: prohibiciones explícitas, abandono de los escenarios tras el matrimonio, gestos de desaprobación, celos profesionales, tutelas directas, control sobre los cuerpos, malos tratos, apelaciones a la vergüenza, la honra o el respeto, permisividad vinculada exclusivamente a lo interiorprivado... Fernanda la Vieja, María Peña, Antonia Pozo, Pepa de Ricardo, Antonia la Reyes, Juana la Feonga, la Morena, la Juanicha, la Perrenga, Luisa la de los Caracoles o La Piruja son algunas de estas flamencas silenciadas que recuerda ahora la fresca y sincera voz de Pepa Vargas desde una clara conciencia de subalternidad, reclamando para muchas de ellas un papel creador pero también delatando su propia comprensión del mundo artístico como una prolongación de "lo doméstico".

Aunque estructurada sobre el ciclo vital de la cantaora (infancia y mocedad desde que nace en 1945, periodo de cuidados como esposa y madre, paso a la profesionalidad y apartamiento final de los escenarios), la biografía es una puerta abierta a la historia del flamenco desde la segunda mitad del siglo XX. Seleccionar este periodo cronológico que, a pesar de su cercanía, ha concitado menos interés biográfico que el de los orígenes o la "Edad de Oro" (1860-1920 circa), convierte a la obra en recurso esencial para la investigación futura. Los recuerdos arrancan en la postguerra, con el deambular por pueblos y ciudades de las compañías de cante y variedades ("los gitanos no iban a escucharlos"), para visitar los años de los primeros tablaos, el revulsivo del neojondismo, la eclosión de festivales y peñas, la expansión mediática del flamenco, la figura del intermediario (impagable los guiños al papel de Jesús Antonio Pulpón), los viajes europeos y transoceánicos, la legitimación del flamenco en los grandes teatros del mundo, y su apertura durante los últimos años a una revolución formal y conceptual sin precedentes, muy alejada de sus previas adherencias genealógica, territorial y estética y ya vinculada a un mercado global y a las nuevas tecnologías. En este aspecto, los autores no olvidan reflexiones indispensables sobre el papel de las culturas locales en la globalización y la génesis de culturas híbridas, el entramado reterritorialización / desterritorialización en el que se sumerge el flamenco contemporáneo, las relaciones entre flamenco y turismo o las encrucijadas entre trasmisión oral y academicismo, aunque sean apenas apuntadas, dada la naturaleza testimonial de la obra.

Al deambular por el mercado escénico (tipologías de artistas, condiciones de mercado, intereses de los públicos...) el texto incorpora, transversalmente, una abundante información de primera mano sobre las fiestas pagadas. Es éste uno de los formatos más duraderos del flamenco, inexcusable para conocer algunos perfiles de ocupación artística de cantaores viejos relegados a las ventas, que complementan así sus ingresos durante los meses de invierno, flamencos a tiempo parcial o pluriactivos, una multiplicidad de situaciones que se recogen bajo la compleja categoría de "profesionalidad". Estas y otras experiencias narradas agazapan, tras la grandiosidad del rito, la cara real pero menos 
reconocida de un arte que, a menudo, prefiere mitificarse a sí mismo: niños dormidos en el seiscientos mientras sus progenitores trabajan en la feria, tiranía (y también prodigalidad) del señorito "roneante", prostitución femenina, hábitos tóxicos inveterados y otros nuevos que van imponiéndose, son algunos de los claroscuros que Pepa cuenta, ora sin pudor, ora con resignación o indignación contenida, pero siempre abriendo el enfoque desde lo personal hacia el contexto social del arte.

Contexto que arranca en una agrociudad de la Andalucía agraria, Lebrija, núcleo de residencia de una amplia comunidad gitana y del que se exponen por igual los nichos laborales gitanos del trato y el campo, la alegría de la fiesta, las enfermedades y las carencias, los modelos de ocio femeninos y masculinos, las pautas de habitación, los juegos y fiestas locales y, sobre todo, la armadura de personajes que construyen el entramado familiar, el entorno humano y las alianzas matrimoniales que sitúan a Pepa Vargas en el centro foco del interés biográfico. Lo que los autores llaman el "derrumbe de un modo de vida" tras la modernización de los años sesenta, el paro y el éxodo rural, la emigración, el tránsito al sector servicios del que Pepa y Curro participaron, los sucesivos cambios de residencia, el salto de los flamencos a los tablaos de Madrid (a destacar la crítica de Pepa a la visualidad femenina y la utilización de las mujeres como reclamo decorativo), o la diversificación de espacios de trabajo y fuentes de ingreso, son algunos de los entramados socioeconómicos e históricos que acompañan la exposición. En este devenir, se adivina el proceso de afirmación como flamenca de Pepa Vargas, su doble expectativa de "ayudar a la familia y realizar un sueño", su afán por promocionar su arte en los escenarios realizando un esfuerzo de re-aprendizaje de los cantes, modulación de la voz, asunción de nuevos procesos creativos y superación de la timidez que le hace alcanzar un papel de "mediadora” para los contratos de la Familia Fernández.

Acompaña a la biografía una magnífica aproximación a las especificidades de los gitanos andaluces, y una serie de consideraciones sobre su "autenticidad" (intuimos que heredera de los asertos de Julio Caro Baroja), que recoge la complejidad de percepciones segmentarias e integradoras de la etnicidad. De una parte, hallamos un discurso sobre la separación entre gitanos "artesanos" y "del campo" en Lebrija y sus asociaciones estilísticas emic (pureza y fidelidad a la tradición / gracia y agachonamiento), la lucha contra los tópicos (como la idea de "clan") o el distanciamiento asertivo de los gitanos andaluces respecto a costumbres propias de gitanos extremeños o madrileños; de otra, y desde una condición amplia de "lo gitano" como "raza" y "sentimiento" a la vez, una reafirmación identitaria acerca de ciertos aspectos del patriarcado, preferencias endogámicas, impermeabilidad ritual o formas solidarias. Y, particularmente, una concepción esencializada y patrimonial del flamenco y las disposiciones para el arte fundamentada en el territorio, la raza y la genealogía. En este último sentido, Pepa hace gala de una encendida defensa del gitano y el mairenismo como comprensión estructurante de "lo flamenco", y nos ayuda a entender 
mejor la pujanza de las propuestas del maestro de los Alcores desde los años sesenta del pasado siglo, descubriendo y afirmando aspectos desconocidos o poco tratados de su figura, como sus apuntes musicales de los cantes para recordarlos y reproducirlos en ausencia de grabaciones, o el contrastre entre una producción discográfica acusada de cierta frialdad interpretativa y su capacidad conmovedora en el entorno de la fiesta.

El flamenco de uso es precisamente otro de los grandes temas de la obra: fiestas para ritos de paso, en los cortijos al hilo de los ciclos agrícolas, juergas entre parientes, amistosas (¡esas visitas de madrugada de los flamencos a la casa familiar!), cantes en las tabernas, fiestas en los patios de vecinos, confraternidad festiva al finalizar los festivales flamencos... La caracterización de estas ocasiones, cuyos elementos de comensalismo, diálogo y risas permiten discutir la solemnidad ritual como única interpretación disponible del flamenco privado, cierra con una encendida y nostálgica defensa del comunitarismo festivo. La perspectiva elegida por los autores recorre tanto la participación de Pepa en las reuniones familiares, como su condición de espectadora en los eventos escénicos, la soledad de la condición de "esposa de artista" - un rol apenas contemplado en los estudios al uso- y la integración como profesional plena. A partir de ahí, la obra se sazona de un juego de dualidades que sintetizan para la cantaora el "antes" y el "ahora" del flamenco: sentimiento / técnica, realidad / virtualidad, proceso / resultado, experiencia / rentabilidad, austeridad / excesos, convivencia / individualismo, tradición / modernidad, que, desde la conciencia de un flamenco arcádico y definitivamente perdido, Pepa prefiere situar como un espacio de nuevas posibilidades para las generaciones más jóvenes.

En esta secuencia temporal, los recuerdos personales van intercalando referencias que nos llevan un viaje apasionante sobre debates y temáticas muy variados. Desde el auge de las discográficas y las tensiones sobre los derechos de autor, al entramado de relaciones amorosas que subyacen al mundo artístico; desde los países más estimados para la artista (destacando Japón), a los cachés de cada momento (¿para cuándo una investigación histórica comparativa sobre los ingresos de los artistas flamencos?); desde las redes de relación de los artistas gitanos con las clases altas (un interesante modelo clientelar en lo social e igualitarista en lo simbólico, que se ha plasmado tradicionalmente en formas de parentesco ritual) hasta la droga o el culto evangélico. Datos que ayudan a revisar verdades preestablecidas pero espurias, como las relativas a los modelos de aprendizaje de los flamencos, que - según se comprueba-deben incorporar al corpus tradicional aprendido en la vivencia de casa y fiesta ("en las fiestas es donde uno mama la verdad") otras muchas influencias, como las sevillanas corraleras de las cruces de mayo, la copla (y aquí el papel de la radio como vehículo de enculturación musical femenina), y hasta los bailes de Coros y Danzas. Por no mencionar el aprendizaje formal y a pie de escenario, en cuya defensa se alza la voz de Pepa como un complemento necesario del aprendizaje "natural", oral o ritual. 
Metodológicamente, la exposición de los contenidos, construidos por igual sobre los hechos y las valoraciones interpretativas, permite varios niveles de lectura y perspectivas analíticas, favorecidos por unos breves párrafos finales que resumen para cada epígrafe las aportaciones fundamentales. Diversas estrategias de redacción motean el texto, haciéndolo ameno y a la vez sistemático: diálogos directos, transcripciones en primera persona, síntesis de los autores, notas y referencias, anotaciones, referencias paralelas y cruzadas... A ellas se unen un apéndice fotográfico final y el prólogo de Ángeles Cruzado, que redondean un trabajo más que bienvenido a la cada vez más ingente investigación sobre temas flamencos, reforzada en los últimos años desde muy variadas perspectivas disciplinares y metodológicas, y a la que han contribuido primordialmente trabajos de investigación y tesis doctorales en el marco universitario de Andalucía y la encomiable iniciativa de editoriales y colecciones andaluzas que, como Athenaica, apuestan por su difusión. 